\title{
The Plagiarism Detection Systems For Higher Education- A CaSe Study IN SAUdi UNIVERSITIES
}

\author{
Yousef k. Sanjalawe ${ }^{1}$ and Mohammed Anbar ${ }^{2}$ \\ ${ }^{1}$ Department of Computer Information System, USM University, Malaysia \\ ${ }^{2}$ Department of Computer Information System, USM University, Malaysia
}

\begin{abstract}
Plagiarism, cheating, and other types of academic misconduct are critical issues in higher education. In this study, we conducted two questionnaires, one for Saudi universities and another for Saudi students at different Saudi universities to investigate their beliefs and perceptions about plagiarism tools.

The first questionnaire was conducted to investigate to which degree the Saudi universities use plagiarism tools. Four universities responded to our questionnaire (KSU, Immamu, PSAU, and Shaqra University).

The second questionnaire was used to investigate the user perceptions toward plagiarism tools in their universities. Forty students responded to this questionnaire. Each student was answered 20 questions. Part of these questions is to measure the confidence of students in terms of referencing; another part is to measure the overall confidence to the system and evaluation of the students' experience. The responses indicate that the respondents believe that some questions reflect their own cases with the plagiarism during their educational lifetime.
\end{abstract}

\section{KEYWORDS}

Plagiarism detection tools, Plagiarism issues, Plagiarism evaluation, students' perceptions.

\section{INTRODUCTION}

The plagiarism problem has lately extended because of the extensive availability of digital resources on the Internet. Plagiarism Detection (PD) has been started since the 1990s basically in Natural Languages (NL) by using statistical techniques, which is promoted by the digital documents and the Copy Detection Mechanisms (CDM) [1], [2]. Software misapplied and code clone's detection has started before plagiarism detection in NL since the 1970s by detecting programming code plagiarism [3], [4] [5].

A lot of researches have been evolved on automated plagiarism detection in NL last decade, based upon the advantages of recent technologies in related fields such as cloud computing, artificial intelligence, and the field of information retrieval.

As we mentioned before, the high availability of the digital documents over the Internet allows the users to build new documents easily by using only (copy and paste). Plagiarism issue occurs when the document content is copied without using citations and permissions.

A lot of plagiarism tools are developed by researchers in order to be used for plagiarism detection but these tools have some difficulties as they cannot show an enough proof that the contents have 
been plagiarized from other sources, PD tools give the similarities and links to some other documents [3],[6].

PD software can be done effectively, if the research have already been published in some global journals. On the other hand, some research centers or universities still do not activate or use PD tools and do not take any action against PD, which encourages researchers to cheat more and more.

Published document's legal issues and copy rights can also be saved by using PD software, so it can classify whether the researchers are legally or illegally copied the documents (i.e.: if the researcher has got the permission from the original owner to use the document or not).

In this paper, we investigate the penalties, consequences, and tools that are used in different counties. After that, this study conducted two questionnaires, the first one is to investigate to which degree the Saudi universities use the plagiarism tools. Four universities were responding to our questionnaire (KSU, Immamu, PSAU, and Shaqra University). The second one is to investigate the user perceptions toward plagiarism tools in their universities. Forty students responded to these questionnaires. Each student was asked 20 questions, part of those questions is to measure the confidence of students in terms of referencing; another part is to measure an overall confidence to the system and evaluation of the students' experience.

\section{LITERATURE REVIEW}

\subsection{Plagiarism definitions:}

Plagiarism as a term originates from "plagium" Latin word, which means "to hijack/ steal a person." Literally, plagiarism means "taking or borrowing someone else's efforts and works and presenting them as the effort of work someone else" [3], [4]

Plagiarism can be defined as "unacknowledged using of programs or documents" [7], but this definition is not clear enough, as it does not explain the term "use" deeply.

Furthermore, Plagiarism can be defined as" the act of stealing/ borrowing the writings of someone and passing them off for the others, which means copyright laws violation."'[8], this definition takes the copyrights into its consideration, as the definition in [7] does not explain the term unacknowledged enough.

The Plagiarism as a term can be defined by different institutions as:

$\checkmark \quad$ Roig M. defines plagiarism as: "Paraphrasing substantial parts or copying of other's work without any contribution in the same work, or using the other's work as your own work ". [9]

$\checkmark$ According to the WAME, plagiarism is "recurrence of six words that follow each other sequentially, or crossing between seven to eleven words into a set that contains of thirteen words. Although, plagiarism is misleading the readers about scientific contribution." [10]

- Using the production without crediting its source.

$\checkmark$ Turnitin.com, and Plagiarism.org are defined plagiarism as:

- Turning the work of someone else's as your own.

- Copying ideas, or contribution, or documents from someone else without giving some credit for the original owner. 


\subsection{Plagiarism types:}

A lot of obfuscation ways can be used to build plagiarized text, that's why we consider plagiarism is very dynamic. Plagiarism can be classified in more than one classification, as the Plagiarism.org classifies it according to the intent of security level. It classifies plagiarism types as shown in table 1 [11].

Table 1: Plagiarism types according to Plagiarism.org [11]

\begin{tabular}{|c|c|c|}
\hline No. & Plagiarism type & Description \\
\hline 1 & Clone & $\begin{array}{l}\text { Steal the whole work (with every small details) of another } \\
\text { person's and use it as its own work. }\end{array}$ \\
\hline 2 & Copy and Paste & Use large part of the text with alternation or citation. \\
\hline 3 & Find and Replace & Keep the original content with changing the main keywords. \\
\hline 4 & Remix & $\begin{array}{l}\text { Use multiple documents and paraphrase them into one } \\
\text { document. }\end{array}$ \\
\hline 5 & Recycle & $\begin{array}{l}\text { It also called (self-plagiarism), occurs when the author use } \\
\text { his old works to form the new work without using citation. }\end{array}$ \\
\hline 6 & Hybrid & $\begin{array}{l}\text { This type occurs when the plagiarist perform improper } \\
\text { citation. }\end{array}$ \\
\hline 7 & Mashup & Combine the text from different resources. \\
\hline 8 & 404 Error & Using citation with invalid or non-existent sources. \\
\hline 9 & Aggregator & No original contribution with valid citation. \\
\hline 10 & Re-Tweet & Use the existing structure with valid citation. \\
\hline
\end{tabular}

\subsection{Plagiarism detection steps:}

Nowadays, PDS is working based on comparing text strings in order to find suspicious similarity between texts. These systems retrieve copied text successfully, but it fails to identify masked plagiarism, like translations, idea plagiarism, or paraphrases [12].

There are three common steps that most PDS have to be followed; these steps are shown in figure 1.

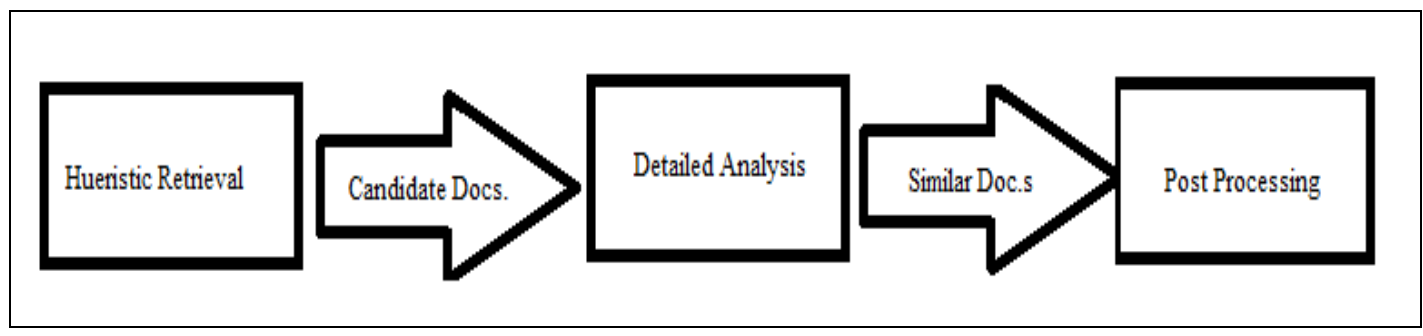

Figure 1: PDS basic steps [12].

During the first step, the plagiarism detection system identifies the candidate collection by applying inexpensive heuristics to determine from which originate the input text has been plagiarized. After that, in the second step, candidate documents that result from the first step will undergo detailed comparison computationally. Finally, PDS must apply post-processing based on knowledge to the segments that result from the second step. 


\subsection{Arabic plagiarism detection system}

An effective document retrieval system (DRS) queries from the Web has been generated in [23]. These developments include three main things: key-phrases informed by keyword's frequency, the first sentence for a paragraph, and variance in readability. The researchers used sizeable corpus in order to empirically evaluate the performance of this heuristics in terms of recall, precision, and f-measure. The proposed DRS shown below in figure, as it consists of the following steps [13]:

1. Suspicious document (D) pre-processing (Tokenization and removing stop words).

2. Using query generation heuristics in order to generate a set of queries $(\mathbf{Q})$ from $\mathbf{D}$.

3. Custom search in Google was used to search Q on the Web.

They concluded that the overall performance of DRS can be improved by combining the previous different heuristics, while the key-phrases based heuristic gives the highest performance across the other heuristics. This work is not considered as stand along plagiarism detection system, rather it is improvement part of the plagiarism detection system that is used to detect Arabic documents.

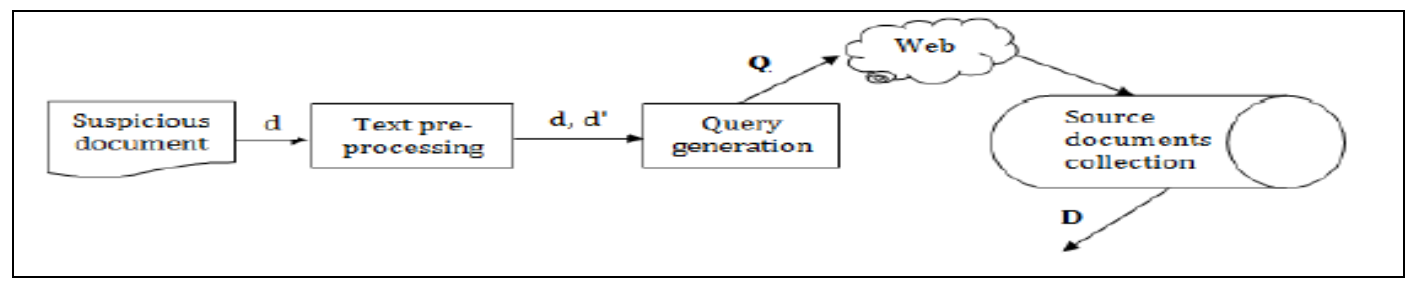

Figure 2: IR system for retrieving given suspicious document from the web [13].

Omar et al. presented a new plagiarism detection algorithm that belongs exclusively to the research that proposed in the health science field in both languages (Arabic and English) [14]. The algorithm is basically built depending on the content comparison that contains string matching and tree matching algorithms. It contains two stages; the first is analysis stage (Cuephrases and complete segment detection, surrounding word's detection, and document segmentation), and the second stage is comparison stage (Cue-phrases, and complete segment's data comparison), as the algorithm architecture is presented below in figure 3 .

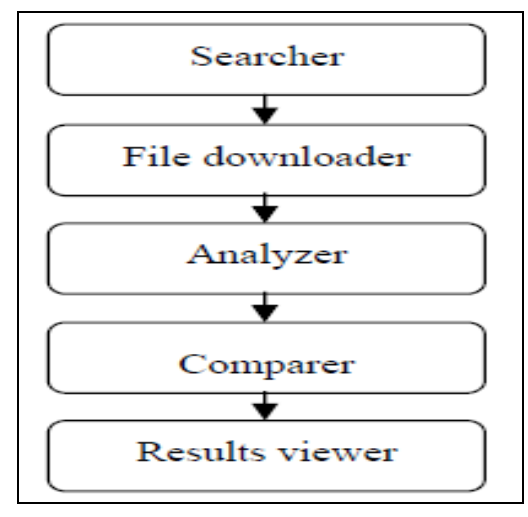

Figure 3: System architecture [14] 
International Journal of Software Engineering \& Applications (IJSEA), Vol.8, No.2, March 2017

\section{Plagiarism Penalties, Consequences, Policies.}

This chapter investigates the plagiarism penalties, consequences, policies, tools, and criteria that are applied in different universities in the advanced countries.

\subsection{Cambridge university}

Cambridge University defines plagiarism as submitting a work which partially or totally derives from the work of others without giving them a credit. It has its own procedure to deal with plagiarism cases.

Examiners are responsible for academic assessment whereas the court of discipline, the University Advocate, and the Proctors are responsible for disciplines.

Plagiarism case, the following procedure must be followed [15]:

1. Determine the significance and extent of the plagiarized material.

Compile and retain all plagiarism clues and evidence like (extracting test from other sources; submitting the same work by other students; originality reports "TurnitinUK"; etc.).

2. Examiners report must include the academic merit assessment for the material. After completing the report, the examiner can contact each other's in order to discuss the work. As the work originality is the main element in the research assessment, whereas the sources must be acknowledged adequately and any person has worked in the submitted work must be indicated clearly.

3. Examiners send the final report to the Secretary of the Degree Committee.

4. Student should precede the oral examination which concentrates on the main academic aspects that are related to the dissertation.

5. Examiners will also submit (the oral examination report, recommendation, and additional report to cover the plagiarism single issue) to the Degree Committee.

6. If the work has been plagiarized, the Secretary of the Degree Committee, the Secretary to the Board of Graduate Studies consultation, and the Proctors will meet the student to investigate the situation.

7. The final award is the responsibility of the Chair of the Degree Committee. That award is allocated based upon the oral examination reports and other supporting clues and evidence.

\subsection{Harvard University}

It is very important to all students to clearly acknowledge when they have incorporated or used the work of others. Harvard University adopted the following policy in order to ensure the correct use of sources [17]:

- As expected, all the student's works (assignments, lab reports, projects, theses, research papers, etc.) will be the student's own. Furthermore, students must differentiate between their own works, knowledge, and ideas and from those that derived from available sources (online or printed published material, opinions and information opinions that directly gained from other people, etc.).

- If the students have to use the text as it, they must use quotations within quotation marks, and they must probably cite that text. Furthermore, all paraphrased texts must be acknowledged and credited completely. Indeed, if the student derives facts or ideas from a student's research or reading, the sources must also be indicated. 
- Students can consult their instructor to learn the proper forms of citation to be familiar with the Harvard Citation Guide to Using Sources.

- If the students submit their works either without clear attention or not own work or idea, he/she will be subject to penalty action, up to withdraw from the College.

- Students who violate these standards are not allowed to submit the course Q evaluation in which the violation occurred.

- If the same (similar) work has been submitted to more than one course within the same college without taking a written permission from the course instructor, he/she is subject to take disciplinary action, and including a requirement to withdraw from the College.

- Students must understand that providing misleading or unrealistic information or signing any other person's plan of study, registration form, change-of-course petition, or on any other petition, form will make them subject to take some of the disciplinary action, up to and including a requirement to withdraw.

\subsection{King Saud University}

Plagiarism can happen for many reasons, not all of them are dishonest. As some students may set out to cheat, and the others just ignore proper citation conventions. King Saud University KSU offers a guide for promoting academic honesty and preventing plagiarism to their students in order to support them to prevent and avoid plagiarism [18].

The plagiarism handbook has the following issues that could be used to support the student effectively [18]:

- An academic context definition plagiarism, examples of plagiarism.

- Describing, in details, different examples of non-plagiarized and plagiarized material.

- Explaining the consequences and penalties of plagiarism to both students and teachers.

- Offering additional resources on plagiarism.

The following table presents the different reasons for employing plagiarism; it also presents the response for each reason.

Table 2: King Saud Plagiarism Penalties [18].

\begin{tabular}{|c|l|}
\hline $\begin{array}{c}\text { Plagiarism } \\
\text { Reason }\end{array}$ & \multicolumn{1}{c|}{ Response for the Plagiarism } \\
\hline $\begin{array}{c}\text { Assuming that the } \\
\text { content on the web } \\
\text { is free to copy. }\end{array}$ & $\begin{array}{c}\text { Conduct them to assure that is wrong consideration, support them to } \\
\text { understand the situation early in the semester. }\end{array}$ \\
\hline $\begin{array}{c}\text { Feeling pressure } \\
\text { from the course, } \\
\text { and using copy to } \\
\text { get through. }\end{array}$ & Encourage, develop, and support them in the class to be more effective. \\
\hline $\begin{array}{c}\text { The assignment is } \\
\text { too complex and } \\
\text { difficult to be } \\
\text { solved. }\end{array}$ & Build an assignment that realize the course material, and that can be \\
\hline $\begin{array}{c}\text { Student with little } \\
\text { planning skills. }\end{array}$ & Build an assignment with previously announced dates. \\
\hline
\end{tabular}


International Journal of Software Engineering \& Applications (IJSEA), Vol.8, No.2, March 2017

\begin{tabular}{|c|l|}
\hline $\begin{array}{c}\text { Fearing from } \\
\text { getting bad mark, } \\
\text { as they have a bad } \\
\text { language or little } \\
\text { knowledge. }\end{array}$ & $\begin{array}{c}\text { Offer practice assignment to improve the student skills. } \\
\text { Encourage and support them by giving your comment and correcting } \\
\text { the errors of that practice assignment. }\end{array}$ \\
\hline Breaking a rule. & Inform the student with the plagiarism penalties and consequences. \\
\hline $\begin{array}{c}\text { They don't realize } \\
\text { the plagiarism } \\
\text { effect on the } \\
\text { others. }\end{array}$ & $\begin{array}{l}\text { Realize this case with the students by assigning an assignment, and take } \\
\text { the optimal assignment and give the assignment credit to another } \\
\text { student. Then, investigate how the original author of the optimal } \\
\text { assignment feels. }\end{array}$ \\
\hline
\end{tabular}

\subsection{King Fahd University of Petroleum and Minerals}

King Fahd University applies the following rules for dealing with plagiarism [19]:

- Plagiarism is a kind of cheating, which is prevented in all of its cases even by instructors or students.

- The course instructor is responsible for evaluating all the student's works in that course.

- In case of plagiarism exist in student work, assignment or project; the course instructor can take any type of penalties up to award a mark of (0) for the student in that work. After that, the instructor should send a report on this case to the head of his department. The head of department sends the report to the Dean of the Faculty.

- Disciplinary committee who investigates the case, and takes a suitable penalty depending upon the extent and degree of that case.

- A student could ask for petition from the Dean of the Faculty within one week starting from the date of informing him/her with taking a penalty decision.

\section{Plagiarism Tools:}

A number of plagiarism detection tools have been produced in order to check the text similarity in different academic institutions in various advanced countries like the US, the UK, Australia, as well as in the Arabian countries like the Kingdom of Saudi Arabia, Jordan, and Egypt. We will focus the following PDS tools to be compared in our research. Table 3 summarizes some of the well-known plagiarism detection tools.

Table 3: Plagiarism detection tools.

\begin{tabular}{|l|l|}
\hline tTurnitIn & $\begin{array}{l}\text { It is checking the plagiarized text by using a digital fingerprinting in } \\
\text { order to match submitted documents against both of in-house } \\
\text { databases, which contains previously attached papers, and internet } \\
\text { resources. }\end{array}$ \\
\hline SafeAssign: & $\begin{array}{l}\text { SafeAssign works by comparing submitted assignments (works) } \\
\text { against a set of identified sources to find areas of overlap (similarities) } \\
\text { between the existing works and submitted assignments. }\end{array}$ \\
\hline PlagiarismDetection.org & $\begin{array}{l}\text { PlagiarismDetection.org provides a user-friendly and innovative } \\
\text { plagiarism prevention and detection online tool that can effectively } \\
\text { help instructors, and students. It is designed to discover all chances for } \\
\text { plagiarized text, and it runs against all the Internet resources, like } \\
\text { online libraries, digital DBs, and websites }\end{array}$ \\
\hline
\end{tabular}


International Journal of Software Engineering \& Applications (IJSEA), Vol.8, No.2, March 2017

\begin{tabular}{|l|l|}
\hline \multirow{5}{*}{ CheckForPlagiarism.net } & $\begin{array}{l}\text { CheckForPlagiarism.net had been created by dedicated instructors, } \\
\text { students, and professionals to provide both offline and online based } \\
\text { plagiarism. They were colluded in order to bring a } \\
\text { CheckForPlagiarism.net which is Document Correction and Plagiarism } \\
\text { Checking product which can combat plagiarism detection during } \\
\text { maintaining intellectual privacy and property of students'. }\end{array}$ \\
\hline PlagScan & $\begin{array}{l}\text { PlagScan is a browser-based service that confirms the documents } \\
\text { authenticity. Files could be attached with all common formats such as } \\
\text { PDF, XLS, MS Word, and many more. PlagScan users can } \\
\text { alternatively paste any text directly into it and check the text } \\
\text { authenticity easily. }\end{array}$ \\
\hline Copyscape & $\begin{array}{l}\text { Copyscape tool is used to online protect your precious contents. It is } \\
\text { considered as one of the most effective tool by large number of } \\
\text { website owners to detect the originality of new content, duplicated } \\
\text { content prevention, and searching of copies of available online content. }\end{array}$ \\
\hline PlagAware & $\begin{array}{l}\text { PlagAware is a multipurpose online-service that provides several } \\
\text { services around the topics finding, analyzing, searching and checking } \\
\text { of plagiarisms. The base element of PlagAware software is a search } \\
\text { engine } S E \text {, which is mainly specialized in detecting identical (similar) } \\
\text { texts contents. }\end{array}$ \\
\hline
\end{tabular}

\section{RESEARCH METHODOLOGY}

To achieve our research objectives, we will use the survey method by applying two questionnaires to collect the data from the universities and graduate or undergraduate students at different Saudi universities. The coding for the conducted questionnaire in this research is presented in APPENDIX 1.

\section{ANALYSIS AND RESULTS}

\subsection{Educational institution's perspective:}

\subsubsection{King Saud University (KSU)}

Dr. Abd Al-Majed A. Al-Elawei who is the Vice Dean of Scientific Research for Technical Affairs in KSU thankfully answered our questionnaire. He ensures that KSU is used the plagiarism tools to evaluate the researches of the staff as well as evaluate the student works.

KSU uses both of IThenticate and Turnitin plagiarism tools to evaluate the researches of staff, and it uses SafeAssign tool that is integrated with the Blackboard website to evaluate the students' tasks and homeworks. Moreover, he ensures that there are some of the written penalties and consequences, as mentioned in chapter three, for the person who plagiarized. Likewise, there are written regulations have been applied at the university about plagiarism.

Al-Elawei said that using plagiarism tools in KSU is optional, and there are no mandatory roles for using it, but most of the instructors preferably employ these tools to evaluate the student's works at different educational levels (BC.s, master, and $\mathrm{PhD}$ ). On the other hand, not all the departments at the university use these types of tools.

The staff and students of KSU are trained for using plagiarism tools in order to encourage them to use these tools to improve their researches and the student abilities for creating their tasks and homeworks. The student has no access for IThenticate and Turnitin, but they only have an access 
for using SafeAssign that stores the previous researches and homeworks in its databases to use it to evaluate any new tasks to the students. The plagiarism tool is working efficiently as it discovered $20 \%$ from the research in the previous years as plagiarized researches.

\subsubsection{Al-Imam Mohammad Ibn Saud University (Imamu)}

At Al-Imam Mohammad Ibn Saud University, Prof. Salah A. Al-makhlof who is an Assistant professor (performing administrative duties) responded to our questionnaire, and ensured that his university uses IThenticate as a plagiarism tool ( to some extent) for checking plagiarism issues with the staff and students.

This university has no written penalties to deal with any person who plagiarized, as using this tool is not mandatory for all departments inside it. In addition, evaluating the works against the plagiarism issues is not applied at all the educational levels. Furthermore, students and instructors were not trained for using this type of tools. The instructors have an access for using IThenticate, but the students have no access on it.

No local or global database stores the pervious researches, tasks, or homeworks in this university to be used for evaluating any new works. On the other hand, clear regulations for plagiarism are applied, to some extent, in this university.

\subsubsection{Shaqra University}

Dr. Omar M. Salah who is an Assistant professor in the collage of science and humanities in Shaqra University responded to our questionnaire. IThenticate software that is related to the Ministry of Higher Education is used at Shaqra University as a tool of plagiarism. Using this tool by the staff is mandatory to evaluate their researches and the student's works, and there are strict and written penalties for the person who plagiarized.

IThenticate is not used to evaluate the students work at every educational level at Shaqra University, and it is not used for all departments inside this university. In addition, the instructors depend on their own capabilities to use this tool, because they were not previously trained to use this tool. The instructors are mostly telling their students how to avoid plagiarism issues, but the students at Shaqra University have no access to IThenticate.

Around $20 \%$ of the research and works of both staff and students in the previous year have been discovered and considered as plagiarized works. The clear regulations for plagiarism are strictly applied in any case of plagiarism.

\subsubsection{Prince Sattam Bin Abdualziz University}

The Head of chemistry department and consultant of vice rectorate of academic and educational affairs at Sattam Bin Abdulaziz University, Prof. Ayman K. Al-sawaf responded to our questionnaire.

IThenticate is also used in this university as a tool for plagiarism. Al-sawaf said that there are written penalties for the person who plagiarized. Using plagiarism tools is not optional in this university, as every instructor must use it to evaluate the student works at Master and $\mathrm{PhD}$ educational levels (i.e. it's not applied to the student in BC.s level). In addition, some departments are only using this type of tools. 
Instructors and students are fully trained to use this type of tools, as well as how to avoid plagiarism issues when doing their educational works. Accessing the IThenticate is only allowed for the instructor, no student can access this tool.

IThenticate had a significant and critical impact while it discovers $20-50 \%$ from the research of previous years as plagiarized works. This huge percentage can clearly show the importance of using this tool for the research field.

All the pervious works (researches, and homeworks) are stored (locally or globally) in the database to be compared with any new works in order to evaluate the plagiarism issues for that works. Clear regulations of the plagiarism are applied in this university. Table 5 summarizes the results of the questionnaire.

Table 5: The First Questionnaire results.

\begin{tabular}{|l|c|c|c|c|}
\hline & KSA & Immamu & Shaqra & PSAU \\
\hline Use plagiarism tool & $\sqrt{ }$ & $\sqrt{ }$ & $\sqrt{ }$ & $\sqrt{ }$ \\
\hline The plagiarism tool name & $\begin{array}{c}\text { IThenticate } \\
\text { Tumitin } \\
\text { SafeAssign }\end{array}$ & IThenticate & IThenticate & IThenticate \\
\hline Written penalties & $\sqrt{ }$ & $\times$ & $\sqrt{ }$ & $\sqrt{ }$ \\
\hline The plagiarism tool is mandatory & $\times$ & $\times$ & $\sqrt{ }$ & $\sqrt{ }$ \\
\hline Plagiarism tool used for all the educational levels & $\sqrt{ }$ & $\times$ & $\times$ & $\times$ \\
\hline Plagiarism tool used in all departments & $\times$ & $\times$ & $\times$ & $\times$ \\
\hline Train the instructors for using the plagiarism tool & $\sqrt{ }$ & $\times$ & $\times$ & $\sqrt{ }$ \\
\hline Taught or trained the student about the plagiarism & $\sqrt{ }$ & $\times$ & $\sqrt{ }$ & $\sqrt{ }$ \\
\hline The students have an access to the plagiarism tool & $\times$ & $\times$ & $\times$ & $\times$ \\
\hline $\begin{array}{l}\text { Percentage discovered plagiarized researches last } \\
\text { year }\end{array}$ & $<=20 \%$ & $\mathrm{NA}$ & $<=20 \%$ & $20-50 \%$ \\
\hline Global or local DB for pervious works & $\sqrt{ }$ & $\times$ & $\sqrt{ }$ & $\sqrt{ }$ \\
\hline Any clear regulation about plagiarism & $\sqrt{ }$ & $\sqrt{ }$ & $\sqrt{ }$ & $\sqrt{ }$ \\
\hline Applying the plagianism regulations & $\sqrt{ }$ & $\sqrt{ }$ & $\sqrt{ }$ & $\sqrt{ }$ \\
\hline
\end{tabular}

\subsection{User perspective:}

The second questionnaire was conducted to measure the students' perceptions at different universities in KSA. Forty-one students have filled the online questionnaire from different Saudi areas with different educational levels. $50 \%$ of them are master student's degree; $45 \%$ are bachelor students, and the remains $5 \%$ are $\mathrm{PhD}$ student. In addition, $75 \%$ of the respondents were males, and $25 \%$ of them are females. Figure 4 and 5 present these percentages.

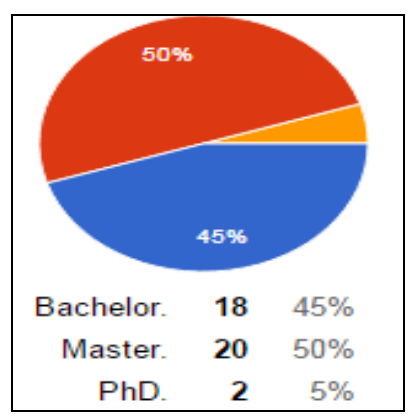

Figure 4: Educational Level. 


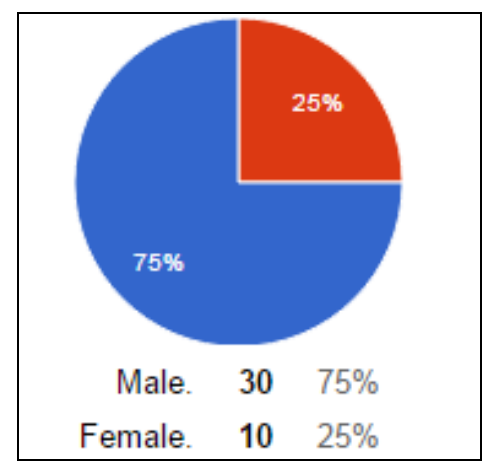

Figure 5: Respondents sex.

On the other hand, the respondents with less than 30 years old are 23 respondents, 15 respondents are between 30 and 40 years old, and only two respondents are above 40 years old.

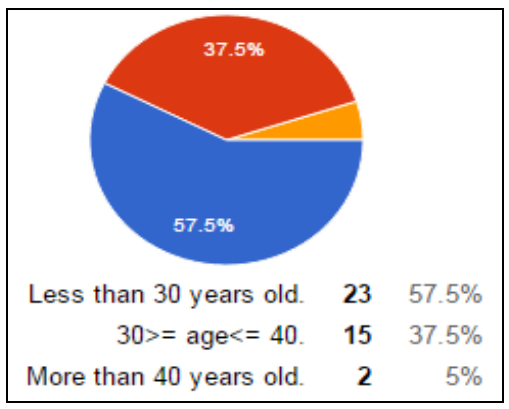

Figure 5: Respondents ages.

Firstly, we were used the next four questions to measure the overall background of the respondents (students) of using plagiarism during their educational lifetime. When we asked them if they have ever used plagiarism tools during their educational lifetime, only $57.5 \%$ of them are personally used plagiarism tools in their educational lifetime when creating their homework and research, and $42.5 \%$ of them are not personally used plagiarism tools when creating their educational tasks. This huge percentage (42.5\%) indicates that most of student don't depend and trust types of tools, or they don't have an enough knowledge and background of the benefits of these types of tools.

On the other hand, $85 \%$ of the respondents (34 students) have heard of the plagiarism concept, and only six students have never heard about this concept. This percentage indicates that the plagiarism concept is not distributed equally over-all educational levels or over-all different educational institutions.

To measure if the plagiarism tool has to address the plagiarism issues related to their educational tasks, the following question was conducted "Has the problem of plagiarism been addressed during your studies?" The results indicate that only 23 respondents have addressed their plagiarism issues by using that type of tools, 10 respondents have not addressed their plagiarism issues, and seven respondents don't know if their plagiarism issues have been addressed by these tools or not.

To measure the confidence of students in terms of referencing; the following questions have been conducted. The first question was "Do you find using the plagiarism tools easy to use?" aims to 
measure the usability of the plagiarism tool in terms of its easiness to use. The results indicate that five respondents have strongly agreed that plagiarism tools are easy to be used, 15 respondents have agreed, 15 respondents have undecided, only 3 respondents have disagreed, no one has strongly disagreed, and only 5 respondents have chosen the average.

In addition, another question, "Is there, as far as you know, a policy for dealing with plagiarism at your institute?" was conducted to measure the confidence among the students in terms of referencing. $37.5 \%$ from all respondents said there is a written policy for dealing with plagiarism at their Institute, $27.5 \%$ of the respondents said there is an oral policy for dealing with plagiarism at their Institute, $15 \%$ from the respondents said there is no policy for dealing with plagiarism at their Institute, 20\% from the respondents don't know if there is a policy for dealing with plagiarism at their institute. These percentages indicate that Saudi universities have started to apply a policy, to some extent, regarding plagiarism issues, which means any new research or educational work, must be novel and has a new clear contribution.

Moreover, when we asked if the respondents find the plagiarism tools are a convenient way to submit their assignments/coursework or not, only 5 out of 41 respondents have strongly agreed, 20 respondents have agreed, 6 respondents have undecided, 5 respondents have disagreed, no one has strongly disagreed, and only 4 respondents have chosen average. This indicates that the available plagiarism tools are trusted by the students to submit their works.

The last question that conducted to measure the confidence among the students in terms of referencing was: "Do you prefer to see your grades electronically on the plagiarism tools rather than on a paper based coursework front sheet?". The result shows $17.5 \%$ from the respondents have strongly agreed to see their grades electronically on the plagiarism tools rather than on a paper based coursework front sheet, $42.5 \%$ from the all respondents have agreed, $22.5 \%$ from the respondents have undecided, $10 \%$ from the respondents have disagreed, $7.5 \%$ from the respondents have strongly disagreed, and no one has chosen average.

The following questions determine the overall confidence to the system and evaluation of the plagiarism tools. Firstly, we determine the confidence of the respondents if they prefer to see their originality report. $25 \%$ of the respondents have strongly agreed that they like to see their originality reports, $52.5 \%$ have agreed that option, $7 \%$ of them have undecided either they like to see the originality report or not, only $5 \%$ of the respondents has strongly disagreed which means they don't like to see the originality report. The results indicate that the originality report is so important for the users (students) to review the checking results and to define the portion of the text which has been plagiarized.

To determine how easy the originality report is, we conducted the following question: "Do you find the originality report easy to understand?. The results in Figure 5.12 illustrate that $25 \%$ of the respondents have strongly agreed that they find the originality report easy to understand, $40 \%$ have agreed that option, $20 \%$ of them have been undecided either they like to see the originality report or not, only $1 \%$ of the respondents has strongly disagreed which means they don't see the originality report easy, and $5 \%$ of the respondents have chosen average. The results indicate that the originality report is almost easy to be understood by the students. As it also reflects the graphical or numerical representation of the results is clear for the users.

To determine how much the students trust the results of the plagiarism tools, they were requested to answer the following question: "Are you afraid that you may be accused of plagiarism based upon the originality report, although it is not true?". A percentage of $15 \%$ of the respondents have strongly agreed that the plagiarism tools result may not always be true, $35 \%$ of the respondents have agreed that idea, $32.5 \%$ of the respondents have undecided, only $2.5 \%$ of the respondents 
have strongly disagreed, and $7.5 \%$ of the them have chosen average. This means, the students don't trust the accuracy of these tools too much. They think that the result of these tools can sometimes be wrong and inaccurate.

To measure the usefulness of the plagiarism tools, we asked the respondents to answer the question: "Do the plagiarism tools make you unsure about what materials you can quote or use in your assignments?". 5 respondents out of 40 have strongly agreed that plagiarism tools make them unsure about what materials they could use in their educational tasks, 18 respondents have also agreed, 10 respondents have undecided, 5 respondents have disagreed which means the plagiarism tools have a positive impact about choosing the suitable material to be quoted. Only 1 respondent has strongly disagreed, as well as 1 respondent has chosen average.

When we asked the respondents if the plagiarism tools make plagiarism a lot harder, 6 respondents have strongly disagreed, 24 respondents have agreed, 6 respondents have undecided, only 3 respondents have disagreed, and only one respondent has strongly disagreed. It means these tools have effectively worked toward their main goal, which is preventing or detecting the plagiarism issues as much as possible.

To use the others' work, you have to quote or relate that work to its owner. To measure how much the students are confident when quoting the others' work, we asked them the following question: "Are you feeling confident about quoting other people's works correctly?". 25\% of the respondents have strongly agreed, which means they are confident when quoting the others' work correctly, $40 \%$ of them have agreed, $20 \%$ of the respondents have undecided, only 2 respondents have disagreed, and 3 have strongly disagreed, and 1 respondent has chosen average. It means most of the students are feeling confident when they are correctly relating the work to its owners. To measure how much the technique and the method of the plagiarism tool work effectively, we asked the following question:" Are the plagiarism tools that you use usually find the sources I use for my assignments?". Most of the students have agreed upon this question. This indicates the tools they used are built on strong text similarity method.

To determine how much the plagiarism tool is reliable, we asked the students to answer the following question "Overall, the plagiarisms tool that you used is reliable?". Most of the respondents (i.e. $47.5 \%$ of them) have agreed, and only $10 \%, 2.5 \%$ have strongly disagreed, and disagreed respectively.

The last question aims to measure the accuracy of the originality report. $10 \%$ of the respondents have strongly agreed, which means they find that the originality report is accurate, $42.5 \%$ of them have agreed, $27.5 \%$ of the respondents have undecided, $15 \%$ of the respondents have disagreed. No one has strongly disagreed, and only $5 \%$ of the respondents have chosen average. Thus indicates that most of students are finding the originality report is accurate. Table 6 summarizes the results of the responses about the second questionnaire (the questionnaire of users' perceptions) 
International Journal of Software Engineering \& Applications (IJSEA), Vol.8, No.2, March 2017

Table 6: Responses of the $2^{\text {nd }}$ questionnaire

\begin{tabular}{|c|c|c|c|c|c|c|}
\hline \multirow{2}{*}{ Question \# } & \multicolumn{6}{|c|}{ Scale } \\
\hline & 1 & 2 & 3 & 4 & 5 & 6 \\
\hline 1 & 18 & 20 & 2 & & & \\
\hline 2 & 23 & 17 & & & & \\
\hline 3 & 30 & 10 & & & & \\
\hline 4 & 23 & 15 & 2 & & & \\
\hline 5 & 23 & 10 & 7 & & & \\
\hline 6 & 34 & 6 & & & & \\
\hline 7 & 5 & 15 & 12 & 3 & & \\
\hline 8 & 5 & 15 & 12 & 3 & 0 & 5 \\
\hline 9 & 15 & 11 & 6 & 8 & & \\
\hline 10 & 5 & 20 & 6 & 5 & 0 & 4 \\
\hline 11 & 7 & 17 & 9 & 4 & 3 & 0 \\
\hline 12 & 10 & 21 & 7 & 0 & 2 & 0 \\
\hline 13 & 10 & 16 & 8 & 3 & 1 & 2 \\
\hline 14 & 6 & 14 & 13 & 3 & 1 & 3 \\
\hline 15 & 5 & 18 & 10 & 5 & 1 & 1 \\
\hline 16 & 6 & 24 & 6 & 3 & 1 & $\overline{0}$ \\
\hline 17 & 10 & 16 & 8 & 2 & 3 & 1 \\
\hline 18 & 6 & 16 & 13 & 3 & 0 & 2 \\
\hline 19 & 6 & 19 & 9 & 1 & 4 & 1 \\
\hline 20 & 4 & 17 & 11 & 6 & 0 & 2 \\
\hline
\end{tabular}

\section{CONCLUSION}

This study was conducted to survey both of educational institutions and students at different Saudi universities to investigate their beliefs and perceptions about plagiarism tools. The first questionnaire was conducted to investigate to which degree the Saudi universities use the 
plagiarism tools. Four universities in this study (KSU, Immamu, PSAU, and Shaqra University). All of the four universities are using the plagiarism tools to different educational levels. The common tool is IThenticate which is used by all universities for the study. KSU uses both of IThenticate and Turnitin plagiarism tools to evaluate the researches of staff, and it uses SafeAssign tool that is integrated with blackboard website to evaluate the students' tasks and homeworks. Regarding the written penalties for the plagiarism cases, only one university doesn't have written penalties this university is Al-Imam Mohammad Ibn Saud University, and the plagiarism tools do not completely use in all of the departments at those universities.

At all of the universities for the study, no students have an access to the plagiarism tools, because those tools only offer organizational accounts (like Turnitin), thus means no student can purchase or use the license of those tools. All of the universities under the study have clear and applied regulations about the plagiarism. On the other hand, each university stores the pervious works (homeworks, researches, etc.) in the global or local database in order to be used to detect the plagiarism issues in the future works.

The second questionnaire was used to investigate the user perceptions toward plagiarism tool in their universities. Each student was asked 20 questions. Part of those questions is to measure the confidence of the students in terms of referencing; another part is to measure an overall confidence to the system and evaluation of the students' experience. The respondents indicated they believe that some questions reflect their own cases with the plagiarism during their educational lifetime.

\section{REFERENCES}

[1] S. Brin, J. Davis, and H. Garcia-Molina, "Copy detection mechanisms for digital documents," in Proc. ACMSIGMOD Int. Conf.Manage. Data, New York, 1995, pp. 398-409.

[2] N. Shivakumar and H. Garcia-Molina, "SCAM: A copy detection mechanism for digital documents," in D-Lib Mag., 1995.

[3] Parker and J. O. Hamblen, "Computer algorithms for plagiarism detection," IEEE Trans. Educ., vol. 32, no. 2, pp. 94-99, May 1989.

[4] K. J. Ottenstein, "An algorithmic approach to the detection and prevention of plagiarism," SIGCSE Bull., vol. 8, no. 4, pp. 30-41, 1977.

[5] K. S. Marguerite, B. E. William, J. F. James, H. Cindy, and J. W. Leslie, "Program plagiarism revisited: Current issues and approaches,” SIGCSE Bull., vol. 20, pp. 224-224, 1988.

[6] S. M. Alzahrani, N. Salim, and A. Abraham, "Understanding plagiarism linguistic patterns, textual features, and detection methods," Trans. Sys. Man Cyber Part C, vol. 42, no. 2, pp. 133-149, Mar. 2012.

[7] M. L. A Joy, M., "Plagiarism in Programming Assignments," IEEE Transactions on Education vol. 42, pp. 129-133, 1999.

[8] Encyclopedia Britannica, http://www.britannica.com/EBchecked/topic/462640/plagiarism (last access March 7, 2015).

[9] M. Roig, Avoiding Plagiarism, Self-Plagiarism, and Other Questionable Writing Practices: A Guide to EthicalWriting.NewYork: St. Johns Univ. Press, 2006. 
International Journal of Software Engineering \& Applications (IJSEA), Vol.8, No.2, March 2017

[10] Masic I. Plagiarism in Scientific Publishing. Acta Inform Med. 2012 Dec); 20(4): 208- 213. doi:10.5455/aim.2012.20.208-213.

[11] Plagiarism.org, http://www.plagiarism.org/plagiarism-101/types-of-plagiarism/ (last access March 7, 2015).

[12] B. Stein, "Principles of Hash-based Text Retrieval," in Proc. 30th Annu. Int. ACM SIGIR Conf.. ACM, 2007, pp. 527-534.

[13] The Implementation of Plagiarism Detection System in Health Sciences Publications in Arabic and English Languages.

[14] Khan K ,et al., "Query Optimization in Arabic Plagiarism Detection: An Empirical Study", I.J. Intelligent Systems and Applications, 2015.

[15] Cambridge Policy, Procedure and guidance for staff and examiners, available at: http://www.admin.cam.ac.uk/univ/plagiarism/examiners (Accessed on 13, May, 2015).

[16] Notes on Plagiarism, University of available at: https://www.leeds.ac.uk/secretariat/documents/cpffm_penalties.pdf (Accessed on 13, May, 2015).

[17] Harvard University Plagiarism Policy, available at http://isites.harvard.edu/icb/icb.do?keyword=k70847\&pageid=icb.page355322 (Accessed on 13, May, 2015).

[18] Plagiarism Handbook, King Saud University, available at: http://35302.wikispaces.com/file/view/Plagiarism+Handbook+2011.pdf (Accessed on 13, May, 2015).

[19] Exams and Research Policies, Handbook of Academic Development, King Fahd University of Petroleum and Minerals, available at: http://www.dcc.edu.sa/downloads/faculty_handbook.pdf (Accessed on 13, May, 2015).

\section{APPENDIX 1}

\begin{tabular}{|c|c|c|c|}
\hline Answer & Code & Answer & Code \\
\hline \multicolumn{2}{|c|}{ From the questions from 8 to 20} & \multicolumn{2}{|c|}{ For question number 2} \\
\hline Strongly agree. & 1 & Male & 1 \\
\hline Agree. & 2 & Female. & 2 \\
\hline Undecided. & 3 & \multicolumn{2}{|c|}{ For the $1^{\text {st }}$ question. } \\
\hline Disagree. & 4 & Age $<30$ years old. & 1 \\
\hline Strongly disagree. & 5 & $30>$ Age $<=40$ & 2 \\
\hline Average. & 6 & Age $>40$ years old. & 3 \\
\hline \multicolumn{2}{|c|}{ For the questions $(4,5$, and 6$)$} & \multicolumn{2}{|c|}{ For question number 7} \\
\hline Yes. & 1 & Yes, a written policy. & 1 \\
\hline No. & 2 & Ye, an oral policy. & 2 \\
\hline Don't know. & 3 & No. & 3 \\
\hline \multicolumn{2}{|c|}{ For question number 3} & Don't know. & 4 \\
\hline Bachelor. & 1 & & \\
\hline Master. & 2 & & \\
\hline $\mathrm{PhD}$ & 3 & & \\
\hline
\end{tabular}


International Journal of Software Engineering \& Applications (IJSEA), Vol.8, No.2, March 2017

\section{AUTHORS:}

Yousef K. Sanjalawe is currently PhD student at National Advanced IPv6 Centre (NAv6), Universiti Sains Malaysia. His research interest includes Data mining, Information retrieval, IoT, and Cloud computing.

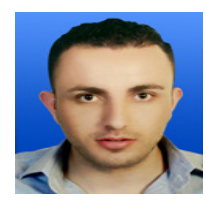

Mohammed F.Anbar is currently a senior lecturer at National Advanced IPv6 Centre (NAv6), Universiti Sains Malaysia. His research interest includes Malware Detection, Web Security, Intrusion Detection System (IDS), Intrusion Prevention System (IPS), Network Monitoring, Internet of Things (IoT) and IPv6 Security.

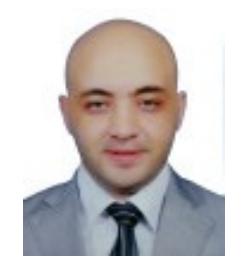

